\title{
Image Experiences in Sandplay Therapy in Adolescents Living in Welfare Facilities Who Suffered Nepal Earthquake
}

\author{
Lee Sehwa* \\ Prakash Shahi* $^{*}$
}

\begin{abstract}
$<$ Abstrat>
Trauma from natural disasters such as the earthquake affected people who have an especially adverse effect on adolescents living in welfare facilities, they suffer psychological distress and post-traumatic stress. This study analyzes the symbols, verbal and non-verbal expression expressed during sandplay therapy for adolescent who suffered the Nepal earthquake and living in welfare facilities. In April 2015, 9 months after the great earthquake in $\mathrm{Nepal}$, sandplay therapy were provided to 18 adolescents living in welfare facilities in the Kathmandu, under the consent of the care-giver, records from three adolescents were provided. The sandplay therapy was conducted one-on-one between a patient and a therapist, for 45-minute each three sessions over 10 days. Sandplay therapy takes a Dora Kalff's approach where a safe and protected environment is provided in a non-directive, non-structured approach. There five themes were commonly found in treatment sessions: Safety and protection, peaceful garden, scene of risk or earthquake, God who is related to everything, and the future of life and independence. In at least two sessions, they have made pictures of direct verbal expression and scene of risk or earthquake, and simultaneously expressed religious image of Buddha or Shiva. Additionally, they decorated a garden praying for paradise or expressed this verbally.
\end{abstract}

Keywords : sandplay therapy, adolescents, images, $N$ epal earthquake, experience

* Counselor, Jeonju Mara Child and Youth Counseling Center (gginmandu@ hanmail.net)

** Trichandra Multiple College, TribhuvanUniversity, Clinical Psychology 
Journal of Symbols \& Sandplay Therapy, Vol.7 No.1.

\section{I . Introduction}

Natural disasters occur frequently all across the globe. In April 25, 2015, a 7.8 magnitude earthquake that hit Nepal killed more than 8,000 people and damaged around 600,000 homes.

Victims of natural disasters like earthquake may experience acute stress responses like depression, agitation, nightmare, fear, dependence and regression (Kim, 2006; Choi, 2006; Le, 2004). When such acute stress responses continue for a month or more, they can develop into a post-traumatic stress disorder (PTSD). According to Lazarus (2003), traumas resulting from natural disasters are extremely dangerous, come without a warning, and are highly destructive. In addition, natural disasters can potentially augment the victims' existing psychological distress by stimulating their past experiences and traumas.

$\mathrm{N}$ atural disaster-related traumas developed in adolescence are closely related to a range of psychological disorders manifested in adulthood. Adolescents require attentive follow-up care as they are especially sensitive to outer environments and have not yet completed their physical, cognitive and personality developments (Cohen, 2003; Allen, 1995). If adequate interventions are not made, adolescents may internalize the stress which can result in impulsive or aggressive behavioral problems; cause them to run away from home or become delinquent; or develop into self-alienation, eating disorder, depression, academic failure and so on (Allen, 1995; Everstine\&Everstine, 1993). In short, natural disaster experienced during adolescence can not only precipitate immediate adjustment problems but also secondary aftereffects in adulthood.

Studies on adolescents victimized by natural disasters have been conducted in full swing in South Korea since 2010, e.g., "The Effect of Adolescents' Traumas and Mentalization Capability on Conduct Disorder" (Choi, 2014) as well as "Plans to Vitalize Guidance and Activities after the Seweol Ferry Incident" (Kwon, 2014). But studies that deal with direct, therapeutic interventions are limited, especially those related to adolescent victims of natural disasters. It is highly important to discover risk factors as well as protective factors related to adolescents' mental shock, and to mobilize both inner and outer resources for their recovery (Oh, et al., 2012).

In the wake of a civil war lasting until 2007 together with deteriorated economic 
conditions, the number of families that could no longer able to provide proper parental care has surged in Nepal. Therefore the number of welfare facilities for children and adolescents run by international relief organizations has risen significantly in the country and, consequentially, so did the number of children entering these facilities. Those living in these facilities are virtually orphans, and most of them had experienced emotional trauma from family conflict and dissolution even before coming to the facilities (Jang, 1995). Plus, living in astrict, systematic group setting makes adolescents have relatively low self-esteem and experience difficulties in self-expression (Kim, 2006).

Prevalent belief of Buddhism and Hinduism in Nepal has led the people to accept and even be resigned to their given situation. The general religious belief among the $N$ epalese is that the cosmos is dominated by a supernatural order under which human beings are subject to obedience. Some view natural disasters as karma, that they are the result of human wrongdoings (Yonhap News, 2015). The Nepalese stress internal peace as taught by Buddha, and do not explicitly express uncertainties and fear in life (Lee, 2015). The religious ideology in $\mathrm{N}$ epal accepts the earthquake as fate. People endure their sufferings by believing that praying to god about their negative emotions like anxiety, depression and resentment will enable them to receive compensation in their afterlife (Cho, 2004).

Adolescents in welfare facilities, who had already experienced traumas in the past, were affected by a secondary trauma after the earthquake. These adolescents were in need of a means to express their inner thoughts that could not be articulated verbally ( $\mathrm{Kim}, 2008$ ), especially as their religious belief deprived them of becoming familiar with communicating negative emotions and as living in a group setting posed difficulties for self-expression (Chae, 2000).

Sandplay therapy is instrumental in reducing clients' behavioral problems by allowing symbolic thinking and practical experience through play (Kestly, 2001). Through symbolic materials like sand and figures, clients are able to understand and express their unconscious thoughts and emotions, as well as increase their inner energy. To be more specific, sandplay helps clients to externalize their problems, through which they are able to address their conflict and trauma and develop a sense of mastery and control, ultimately being able to resolve 
problematic situations ( $\mathrm{K}$ alff, 2003).

This research aimed to grant opportunities to adolescents who experienced the 2015 $N$ epal Earthquake to express their emotions and help them overcome their traumas through sandplay therapy, as well as to study how the their experiences are represented through sandpicture images.

\section{ПI. Mathod}

\section{Participants}

Individual sandplay therapy was given for a period of 10 days to 18 adolescents aged 14 to 18 living at a welfare facility, nine months after the $2015 \mathrm{Nepal}$ Earthquake. During the first session, the program's structure (i.e., time and space), study objective, content and process were elaborately explained to the participants. It was also during the first meeting that all participants agreed to have each session videotaped and sandpicture photographed. This paper presents the sandplay cases of three participants-Skal (age 17), Rosie (age, 15) and Rookie (age 18)-who agreed to have their processes published. Not that the names of the clients have been changed.

The participants were living in a facility situated in the capital city of Kathmandu, where the earthquake had hit the hardest. When the tremors were felt, they managed to evacuate outside but at the same time witnessed other children at the facility getting injured and neighboring houses collapsing. Everyone at the facility had to live together in makeshift tents for a week, and several aftershocks occurred even afterwards. At the time of therapy, the participants were back in the facility building.

\section{Research Process}

The study made phone calls or sent written letters or emails to welfare facilities in Kathmandu in search for potential participants. Among the contacted facilities the study chose 
Facility D, as it was highly willing to cooperate and also as obtaining consent from parents or legal guardians was possible. One-on-one individual sandplay therapy sessions were conducted in the director's room and another small room within the facility. A total of 3 sessions over a period of 10 days was given to each participant. The sandplay therapy provided in this study took a Kalffian approach, meaning that the participants engaged in non-directive, unstructured play in a free and protected space.

\section{Sandplay Therapy}

\section{Skal' Case}

Skal was a 17-year-old high school boy who went into the facility due to financial reasons. The exact date of entrance could not be recalled. $\mathrm{H}$ is mother lived in Malaysia, father in a region of $\mathrm{Nepal}$, and his younger brother in Spain where he plays football. At the time of the earthquake, Skal was inside the facility but quickly evacuated with other children without any injury. He enjoyed school life, liked studying science, and wanted to become a doctor and live together with his family in the future. Themes of protection and safety, peaceful garden, god or daily life with god, future life, and independence frequently appeared in his sandpictures.

In his first sandpicture (Figure 1), Skal stated that house is very important to human beings as it provides all things that are necessary and important. In the left rear quadrant is a house and in the right rear quadrant, standing symmetrical to the house, is a similar-sized Buddha figure. Pointing to the Buddha figure, Skal said that it is his favorite god whom he hopes to emulate. Standing in front of -though not directly in front-the house is a dog, and Skal explained that the dog is guarding the house and that it barks when someone approaches. He added that the cow next to the dog is the god or the goddess whom he worships; it provides milk, cheese, butter, and other items. In the near half of the sandtray is a large snake which, as Skal explained, could be a Mandala snake and is a frightening, dangerous animal that can kill people. Overall, the traumatic experience of the earthquake seemed to have 


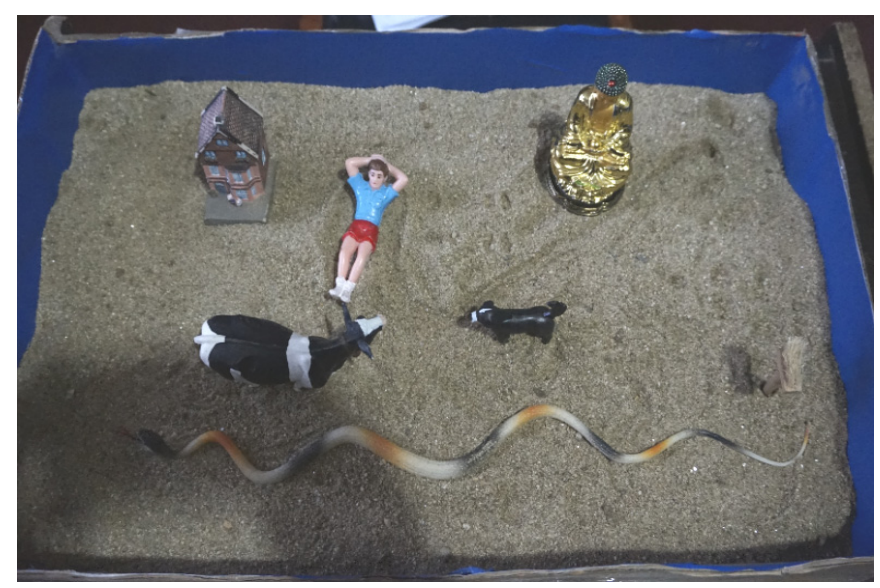

Figure 1

evoked emotions such as uneasiness and anxiety of the past. Concrete reasons for those emotions may vary from his current environment and familial issues to other traumas; nonetheless he exhibited uneasiness.

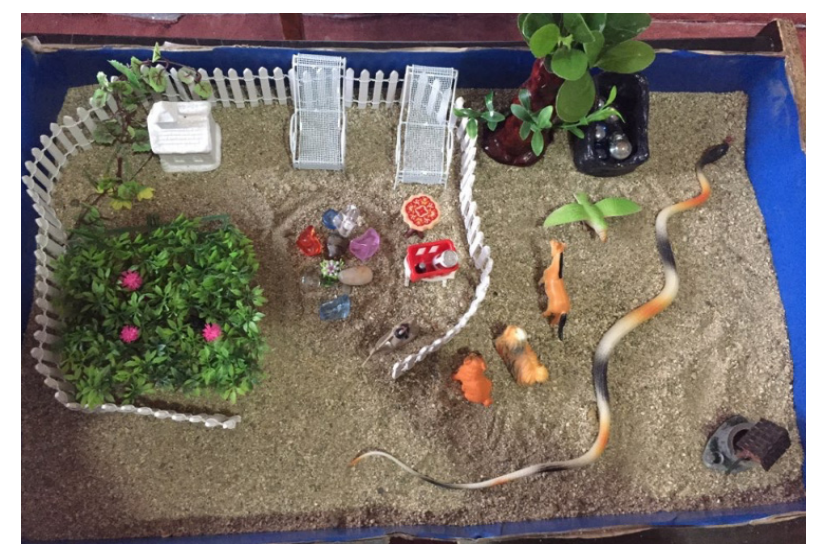

Figure 2

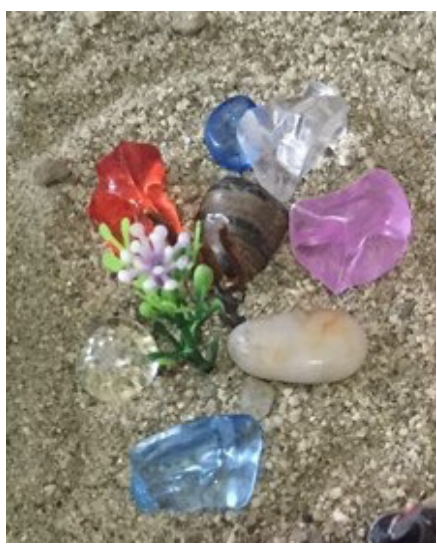

Figure 3 (Details of Fig. 2)

The most salient part of Figure 2, in contrast to Figure 1, is the fence that surrounds the house. In Figure 1, a cow (the god/goddess whom Skal believes in) and a dog were protecting the house. In Figure 2, the fence was playing the role of the cow and the dog. Is the client trying to protect himself, his turf, and his dream from the fearful, threatening snake? When asked if he had dreamt after the first session, Skal replied that in his dream he 
saw a large, dangerous snake that was observing a bird laying eggs. As soon as the bird sat down, the snake ate the bird. This dream reflected his reality. In the dream a dangerous snake devoured a bird, and in reality Skal was finding it difficult to protect the possibilities he had hoped for. In fact he expressed dissatisfaction over the reality while selecting the figures:

"I wish that this figure (referring to the Indian figure holding a spear inside the fence) was bigger."

"Do you think the small puppy can save me?"

The area almost at the middle of the fence with glass beads and a trident is a garden, which Skal referred to as "safe" and "a beautiful, peaceful place." The glass beads were a signal for protection to his guardian Shiva, the Hindu god. When he needed help or rescue, he could send a signal through this formation. Skal added that meeting the therapist was also a help sent by Shiva. Hence, the signal sent out to Shiva is a symbol that represents his hope to receive protection from danger or to escape from pain.

Skal then talked about Shiva's third eye, which opens up when the god becomes enraged. Shiva, having a dichotomous character of being a protector and a destroyer, can be seen as a personification of Skal's own anger. Whereas Skal remained expressionless in the first session, his face conveyed anger in the second session and his verbal responses increasingly evinced dissatisfaction.

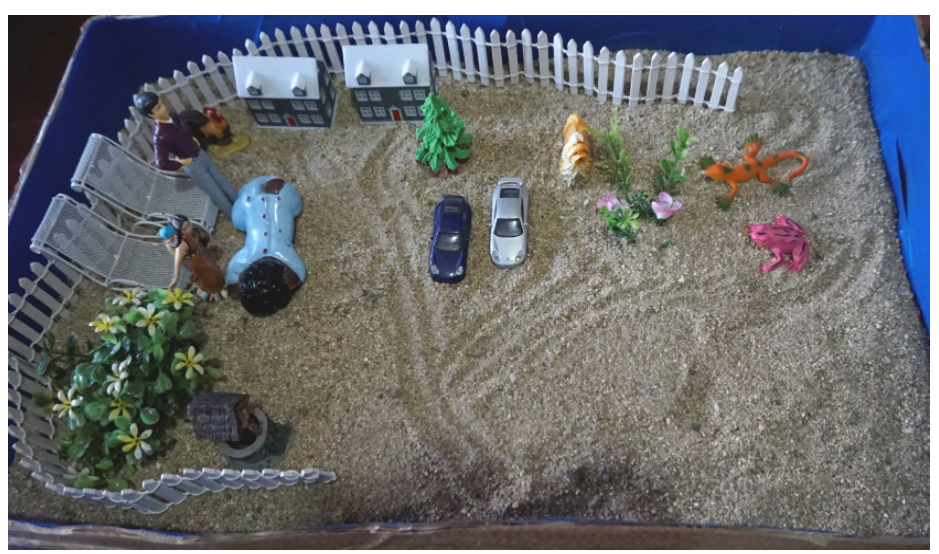

Figure 4 
Journal of Symbols \& Sandplay Therapy, Vol.7 No.1.

During the third session (Figure 4), Skal repeatedly hummed, "Home, home. My home," while creating his sandpicture. Pointing to the sandtray with a smile on his face, Skal said that he wants to build a home similar to the house figures and live in it with his family members and a dog. Figure 1 and 2 represented Skal's wanting for god's protection and safety. In contrast, Figure 4 represented his future life: the wish to be at peace under the protection of god and to become independent from the facility. The two cars can travel anywhere; they symbolize Skal's inner healing energy. Marks made on the sand that connected the houses, garden, family and frogs reminded the therapist of the tree of life.

\section{Rosie's Case}

Rosie, a 15-year-old girl in the eighth grade, had lived with her grandmother until the age of 7 before moving into the facility. Her birth mother died when Rosie was around 12. Her biological older sister and younger brother lived elsewhere. Her father lived with her stepmother, two younger half-sisters and a half-brother. Rosie lived with her aunt and her family at the facility; the aunt was a cleaning staff. Rosie was lying on top of a bunk bed when the earthquake occurred, and she ran quickly outside with other children. While conversing for the first time with the therapist, Rosie coughed several times with each cough lasting a minute or two, as if she suffered from asthma. Rosie explained that her respiratory system had been weak since childhood and it worsened after the earthquake. So she had been taking medications which improved her condition. During sandplay therapy, Rosie primarily expressed themes of danger, god, protection and safety.

The left near quadrant of Rosie's first sandpicture (Figure 5) contains a bed and a girl looking at a mirror, unaware of the dangerous situation behind her where a snake and a tiger are in a confrontation. Rosie was in bed at the time of the earthquake, and when the tremor began she quickly ran out with other children. This unconscious trauma was communicated indirectly through the sandpicture. Rosie called the widemouthed snake a large anaconda, adding that it was very strong and scary. The snake symbolizes the earthquake, the danger that occurred abruptly.

Though Rosie did not verbally mention the earthquake in the first session, direct 


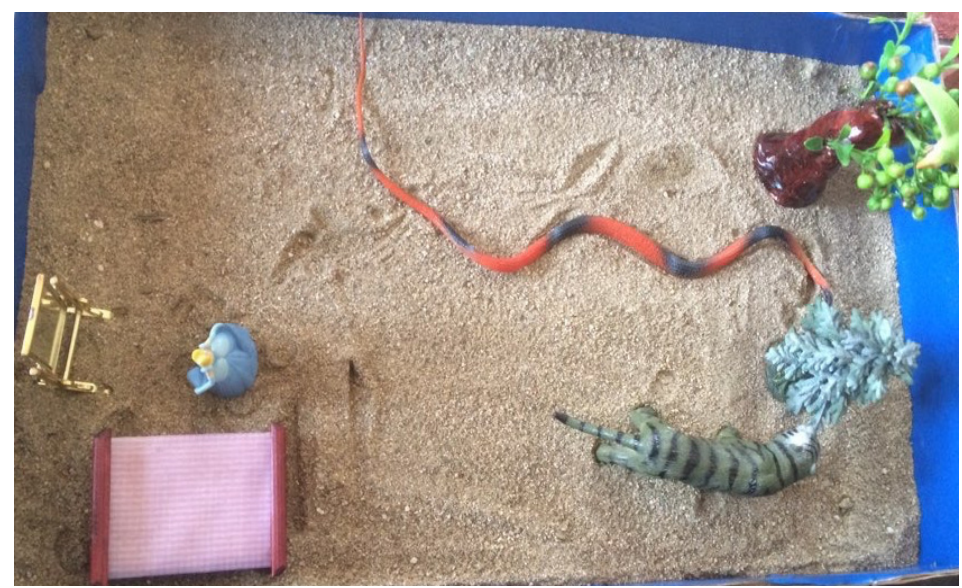

Figure 5

reference to earthquake and the energy of restoration emerged in the second sandpicture (Figure 6). In fact, Rosie's cough subsided, her verbal explanations increased, and she hummed and displayed a more comfortable demeanor.

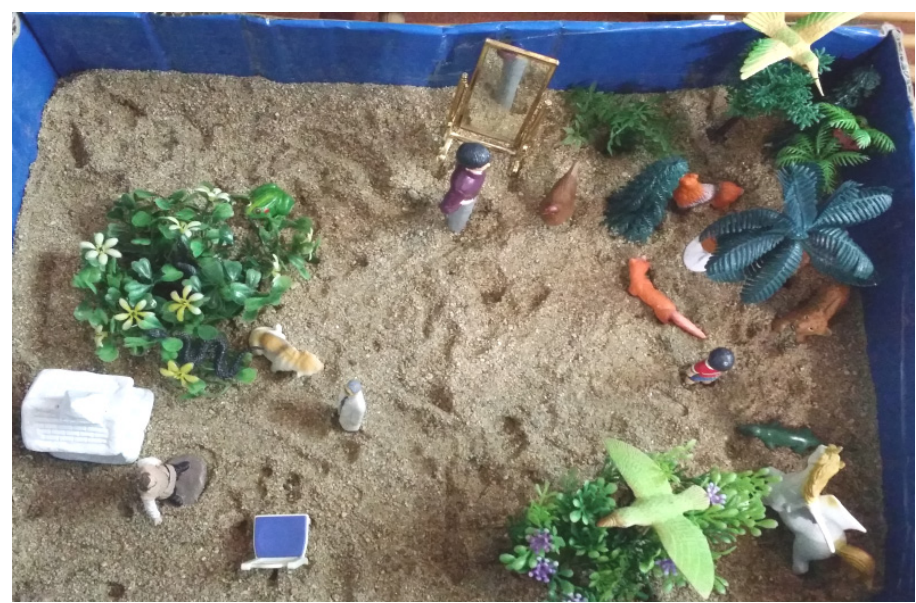

Figure 6

In the second sandpicture (Figure 6) are marks made on the sand, a dog protecting a white house, and a doctor heading towards the house. Rosie directly commented on the earthquake and portrayed the situation of $\mathrm{N}$ epal at the time in her sandpicture. Then she spoke about the cow and how everything relates to god: 
Journal of Symbols \& Sandplay Therapy, Vol.7 No.1.

"This is a city called Kathmandu. It's a dark night and people started to come in from abroad."

"Everyone died but the doctors saved them"

"The cow is the god whom we believe in. [The cow] gives us many things and everyone loves the cow. The doctors, foreigners, and you (looking at the therapist) have all come because of god!"

\section{Rookie's Case}

Rookie was an 18-year-old high school boy. He did not share the story of his family. When the earthquake hit, he was up on a ladder. He quickly came down, took the kids around him and ran outside. He said he had been depressed since then, and the depression had exacerbated after hearing new reports about the damages and deaths in other regions. The depression was so bad that he would sometimes continue to sleep for a day or two straight. He complained of occasional nightmares as well as somatic symptoms like mild headache, sleep deprivation, infrequent fatigue and body aches, which began a few days after the earthquake. Rookie mainly conveyed themes of protection and security, danger or earthquake, god and shrine, and peaceful garden through his sandpictures.

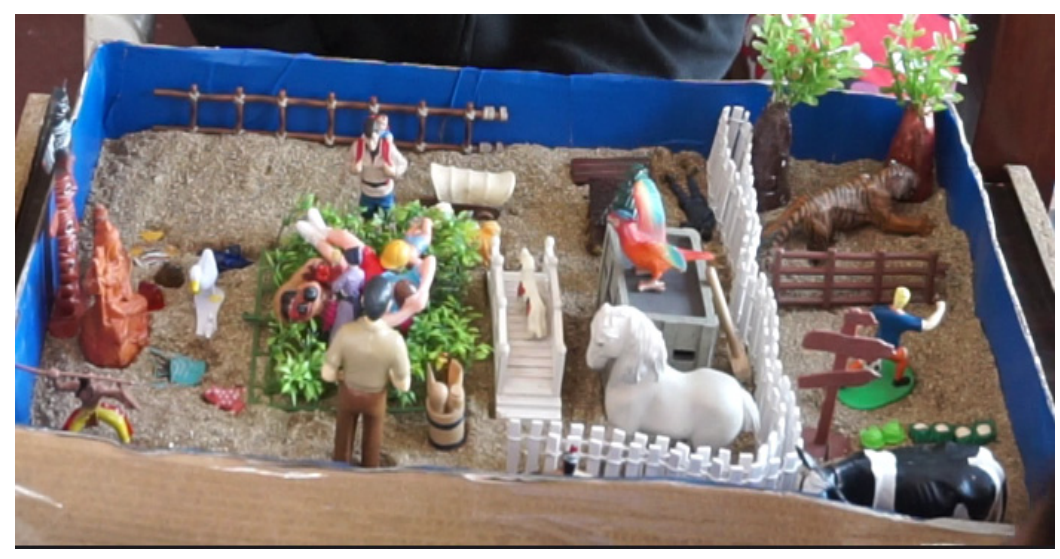

Figure 7

Rookie's first sandpicture (Figure 7) has a Shiva figure on the left side of the tray. Food and animals placed in front are offerings to Shiva. Rookie said god Shiva gives and 
protects lives. He (Rookie) can sometimes talk to the god when he is bored. Overall the picture depicted the close relationship with god in everyday life. At the center is a bird sitting on top of a cracked building, and next to it are a broken bridge and a police officer lying down. Fences are placed around the tiger in the right rear quadrant as it is dangerous. Here the tiger may represent the earthquake and the possibility that the symbolic life can again become shaky; thus the fences were used as symbols for Rookie's daily life and for the protection of that life.

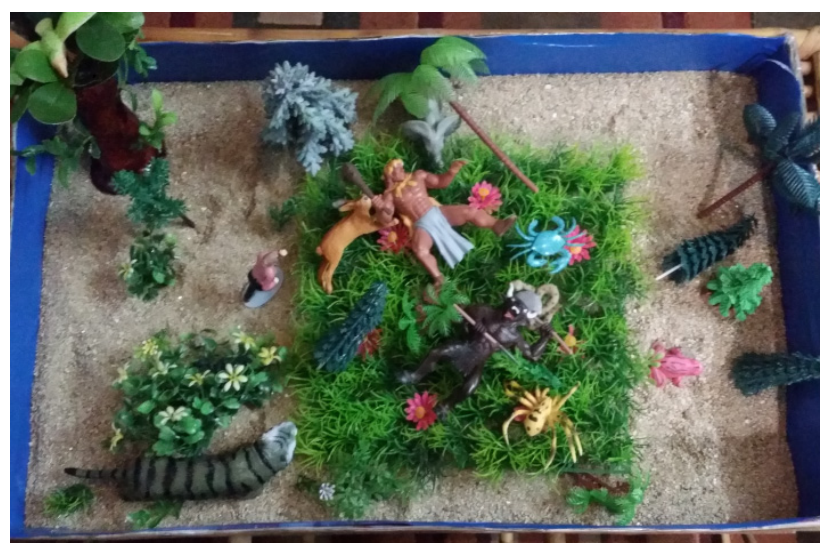

Figure 8

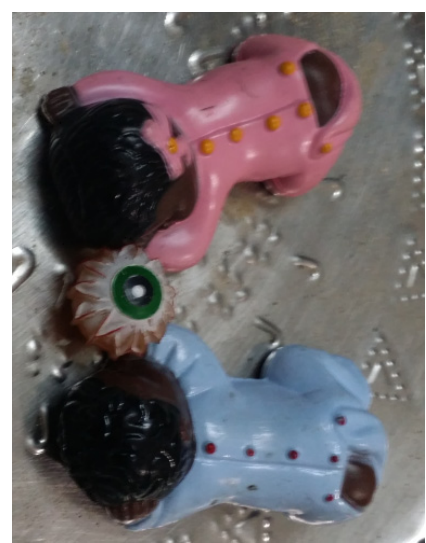

Figure 9 (The eye in the dream)

Biblical representation of the fence is protection by God (Job 1:10). On the contrary, removing the fence represents invasion by the enemy. Just as the thorn-fence was set up to demarcate and prevent predators and wild animals from entering (Mark 21:33), it seemed that Rookie wanted to protect himself from danger and maintain a safe state.

Rookie recreated the dream he had after the first session. In the dream he was home alone. Then he was running endlessly to get away from someone, and huge giant and monsters were chasing after him. A gigantic eye stared at him, and a big blue tiger with white fur on the face, the giant, and monsters caught him. Rookie reported having had similar dreams intermittently after the earthquake. The fallen trees, small animals and people running seemed to portray the tense and horrifying moments during the earthquake.

In regard to the gigantic eye and the large tiger that appeared in the dream, the 
Journal of Symbols \& Sandplay Therapy, Vol.7 No.1.

therapist made an association to the Hindu myth which tells that fire emitted from Shiva's third eye turned into a white tiger. An association can also be made to Cyclopes, Greek mythology giants known for brute strength and power with a single eye in the middle of their forehead, or to DoahSohor, a spiritual figure in Mongolian mythology who has eyes with clairvoyant powers and thus can foresee a destination three days away. It is the eye of a god, able to penetrate into everything.

\section{Method of Anelyes}

Thorough explanations about the study was given to the participants and their consent was obtained in advance in order to meticulously analyze both their verbal reports and nonverbal behaviors. Detailed anecdotal records were written about the entire process of sandplay therapy, including the participants' behaviors, verbal statements and explanations of the sandpictures. Also, all sessions were videotaped and all sandpictures were photographed.

In order to categorize the themes that appeared in different sandplay cases, the therapisttook notes of her observations and comments on the spot (Kim, 2008), and also of the contents that were found to be meaningful after the entire three sessions of sandplay therapy, the purpose of which was to develop a focus at the narrow end of the "funnel"(Bogdan \&Biklen, 2006). Reviewing and reexamining the notes multiple times, the therapist identified different themes, classified each sandpicture under the identified themes, and interpreted the sandpictures. The sandpictures were interpreted based on the followings: verbal and nonverbal expressions of the participants; symbols that represented experiences relating to the earthquake; symbols connecting to the life at the facility; symbolic narratives; fairytales, myths and folktales related to the image; and an understanding of the participants' symbolic languages based on their collective and personal aspects including their background, major problems, dreams and so on.

In order to minimize possible errors, data collection and analyses were done in various ways: participant observation, interview, data collection, filming and photography (Kim, 2008). And building on the analyzed data, observer's records, and photographs of the sandpictures, the 
study result was further modified and supplemented through a peer supervision with a trained sandplay therapist.

\section{CASE ANALYSS}

Though the participants were each given only three sandplay therapy sessions, they exhibited feeling better and happier after talking about their stories. They also reported that the therapy provided them an opportunity to think about their future.

The following five themes could be seen commonly in the participants' sandpictures: protection and safety, peaceful garden, danger or earthquake, god or their daily lives with the god, future life and independence.

\section{Protection and Safety}

The first theme was literally about protection and safety, which connected to their past traumas and the recent earthquake. Most adolescents at welfare facilities in $\mathrm{Nepal}$ have been separated from their families for more than 7 years. Their parents were either living in other parts of $\mathrm{N}$ epal with their new families or overseas, so in a sense the participants themselves were their own chaperones. The participants displayed this theme mostly by using human or animal guardian figures, or fences.

\section{Peaceful Garden}

Peaceful gardens were created primarily with plants and domestic animals. According to Buddhist tradition, Siddhartha Gautama, or the Lord Buddha, was born in the gardens of Lumbini in Nepal (Yonhap News, 2015). Symbolically, the garden is a paradise as well as a dwelling place for the blessed; it also symbolizes an organized nature (Lee, 1994). Peaceful garden scenes represented the participants' wanting for their physical and psychological confusion and instability - which resulted from family separation and the earthquake-to become like a 
well-kept garden.

\section{Danger or Earthquake}

The participants depicted the actual earthquake they had experienced. The theme of danger was illustrated through the appearance of an aggressive snake and a battle between animals and people.

\section{God or Daily Lives with God}

The participants placed god figures or created a shrine scene in the sandtray and offered verbal explanations. Figures used to represent god were Buddha, Shiva and cow. The participants mostly referred to Hinduism. They believed that the gods will help them and that the earthquake as well as their current situations were all according to the divine will.

\section{Future life and independence}

The participants are to be discharged from the facility when reaching the age of 19 . Their sandpictures indirectly portrayed the dreams of their future, hope of living together with their separated families, and preparations for an independent life.

\section{Condusion and Disasion}

This research provided adolescents residing in a welfare facility, who experienced the 2015 Nepal earthquake, an opportunity to express their emotions connected to their past and present experiences through sandplay therapy.

The sandpictures mostly represented the participants' past traumas and the earthquake experience. Creative activities and symbolic images were conducive to the participants' healing. Sandplay therapy allowed them to express repressed emotions as well as positive emotions. They 
reported feeling better after therapy and about how the therapy had given them an opportunity to mull over their dreams for the future. The participants represented the earthquake and the damages it brought either directly, or indirectly through snakes, Shiva and threats posed by animals and monsters.

These participants not only experienced traumas before coming to the facility but also witnessed destructions and deaths in the wake of the earthquake with their own eyes. Bearing this in mind, the therapist saw that many of the sandpictures portrayed peaceful gardens that conveyed the hope for a paradise.

These participants not only experienced traumas before coming to the facility but also witnessed destructions and deaths in the wake of the earthquake with their own eyes. Bearing this in mind, the therapist was able to see that many of the sandpictures portrayed peaceful gardens that conveyed the hope for a paradise.

That the three adolescents were able to overcome their trauma through their relationship with gods could be observed in therapy. In fact, all three of them created scenes related to, or made verbal references to, Shiva, Buddha and cow.

Shiva not only encompasses but also goes beyond all conflicts and confrontations in life; he is a god of transcendence. $\mathrm{He}$ is known as the god of death and destruction, having three eyes and five faces. This god of destruction dismantles and destroys the cosmos, and reverts it to a state before creation (Se0, 2002). The participants' sandpictures and verbal statements may be related to their past traumas. But in their view, the earthquake is the divine will of god Shiva who prepares for creation through destruction.

The gigantic eye that observed everything in Rookie's dream represents god Shiva, who is known to have three eyes. It implies that the current situation in Nepal is according to the divine will. In alchemy, the third eye is referred to as a door that leads to a place of higher consciousness, the inner realm. One of the names identified with Shiva is "Tryambakam," which means "having three eyes." The Hindu religious texts Puranas tell the story of Shiva's burning Kama (a god sent to console Shiva's grief) to ashes by emitting the fire of rage from his third eye, and later restoring him to life. According to a different myth, the third eye is supposed to have appeared when Shiva's both eyes were covered. Immediately 
Journal of Symbols \& Sandplay Therapy, Vol.7 No.1.

the universe was plunged in darkness, and chaos reigned supreme. Shiva formed the third eye to restore order and fire emerged from his third eye to recreate light in the universe (Seo, 2010). The three eyes of Shiva also exist on his weapons; in many sculptures and pictures he is depicted as holding sometimes a bow, sometimes a trident spear, and sometimes both. The $\mathrm{H}$ indus believe that these weapons symbolize a protective force that safeguards the people from difficulties.

The use of Shiva and cow figures in scenes related to past traumas and the earthquake was interesting. That religion plays a pivotal role in the participants' psychological reconstruction was represented in the pictures.

In this study, sandplay therapy facilitated the participants' development of means to overcome or cope with their experiences and psychological distress, by enabling them to express their emotions connected to past traumas and the recent natural disasters both verbally and nonverbally. A common ground was found among the three adolescents in that they all used figures representing god in their sandpictures. This was closely related to the religious culture in $\mathrm{N}$ epal, which greatly influenced their expression of emotions.

One of the major limitations of this study was that it was not able to explore factors related to the participants' living environment prior to entering the welfare center: family history, relationship with primary nurturers, etc. Many follow-up studies complementing these shortfalls therefore will have to take place in the future. And as revealed through this study, future studies should bear in mind religious beliefs of the Nepalese must be taken account when dealing with the traumas of adolescents resulting from the Nepal earthquake.

\section{References}

Minyeong Kwak (2015). Posttraumatic growth and related factors in firefighters. (Master's thesis). Inje University. Gimhae, Korea.

$\mathrm{MiH}$ young $\mathrm{Kim}$ (2008). Effects of SandPlay therapy on the Self-esteem oflong-term Institutionalized Adolescent. (Master's thesis). Daegu University. Daegu, Korea.

Minjung Kim $\cdot \mathrm{KyungHa}$ Lee (2014). The effect of the directed group sand tray play on the 
self-esteem improvement in withdrawing youth. The Journal of Play Therapy, 18(1), 29-55.

Kim, S. Y. (2008). A Study on Group Composition, Materials, Theme Choice in SandPlay of Five Y ear Old Kindergarten Children: An EthnographicStudy. (Master's thesis). Ewha W oman University, Seoul, Korea (Master's thesis).

Kim, Y. J. (2002). The Mediating Effects of Cultural Variables on Somatization. Graduate School of Korea University

Shin, H. K. (2000). The Relationship of Academic Stress, Negative Affectivity, Alexithymia, and Perceived Parenting Behavior to Somatization in Adolescents. The Korean Journal of Clinical Psycholosy. 21(1), 171-187.

Yang, M., Lee, E., Choi, J. W., Kim, H. J. (2012). PTSD and Related Factors among Dispatched Firefighters to Rescue Sites after the Great Japanese Earthquake. Annals of Ocaupational and Environmental Mediane 24(2), 167-179.

Oh, H. Y., An H. Y., Kim E. Y. (2012). A Review of literature on Psychosocial Interventions for Disaster-affected Adolescents. Korea J ournal of Y outh Counseling, 20(2). 335-360.

Lee Y. J. (2004). Psychological Effects of Disaster and Strategies of Psychological Assistance for the Recovery from Disaster: Child-Focused Approach, Korea Journal of Youth Counsel. 12(1), 28-40.

Jeong, S. W. (2002). The Influence of Original Family Relationship on Psychosocial Adaptation of Adolescent in Institutional Care. Journal of Korean Sodety of Child W efare, 14. 145-166.

Chae, Y. S. (2000). Threapeutic case studies of Maladjusted children with sandplay Box. (Master's thesis). Kyung Heel University, Seoul, Korea.

Choi, N. H. (2006). Establishing the Public Support System for Disaster Survivors. Crisisonomy, 2(2), 1-18.

Kim, G. T. (2006). Crisis of Everyday Life and Overcoming Crisis (3rd ed.). Paju : Daewangsa, Korea.

Kim, D. H. (2016). "A year ago, the Great Earthquake in Nepal, but still far from being recovered ...". Chosun.com. 2016. 04. 22.

출처 : http://news.chosun.com/site/data/html_dir/2017/04/18/2017041801554.html

Gu, B. Y. (2001). Disaster Prevention Manual for Disaster Prevention. Korea Youth Counselling \& 
Journal of Symbols \& Sandplay Therapy, Vol.7 No.1.

W elfare Institute.

Kim, E. H. (2006). Effect of Solution-Focused Group Art Therapy Program on Mental Health and Stress Coping Skills: The Case of Institutionalized Adolescents. (Doctoral thesis.) Hanyoung Theological University, Seoul, Korea.

Kim, J. E. (2016). The Intimate B ond. Seoul : Banni, Korea.

Kim, H. B., Seo, W. S., Gong, J. S., Bae, D. S. (2014). Clinidan-Administrated PT SD Scale of Korea for Children and Adolescent. Seoul: Maxmedica, Koera.

The Great Encyclopedia of Religious Science. Korea Dictionary Research Publishing. (1998. 8. 20). 'Eye'.

Cho, J-H. (2004). U panishad philosophy and Buddhism. Seoul: Kyunseowon, Korea.

Scholz, W. (2000). Trans, Hwang Seon-Sang. Hinduism. Seoul: Yekyong, Korea.

J oongang (2015). Nepal's Religion, Hinduism, Buddhism, Islam … Nepal's Religious Status? 2015. 05. 01. http://news.joins.com/article/17719462.

Cooper, J. (1978). Trans, Lee Yungi. (An)llustrated encydopaedia of traditional symbols. Seoul: Kachi, Korea.

Masako, N. (199). Trans. Jang, Y oung-In. Crisis of child care and sodal protection. Seoul: Human wellbeing, Korea.

Yonhapnews (2015). <Nepal Earthquake> How do you view Hinduism, Buddhists, and disasters.

http://www.yonhapnews.co.kr/bulletin/2015/04/27/0200000000AKR20150427160100009.HTML 